\title{
Estado da questão sobre a formação profissional de psicologia frente a situações de violência, intolerância e racismo por motivações religiosas
}

\section{Status of the question about professional psychology training facing situations of violence, intolerance and racism for religious motivations}

\author{
Marcos Teles do Nascimento ${ }^{1 *}$, Marcus Cézar de Borba Belmino²
}

\begin{abstract}
RESUMO
Trata-se um estado da questão que busca compreender o cenário de pesquisas sobre a formação profissional em Psicologia frente a situações de violência religiosa, intolerância religiosa e racismo religioso. Para tal, metodologicamente, adotou-se como fonte de pesquisa a Biblioteca Digital Brasileira de Teses e Dissertações - BDTD entre os anos de 2010 e 2020. Além disso, adotou-se palavras-chave no campo de busca como forma de seleção dos materiais coletados. Após isso, foi feito uma leitura inicial dos resultados em que o pesquisador observou título e resumo da pesquisa, resultando em um percentual menor de materiais, dissertações e teses, que foram lidas na íntegra e apresentadas nos resultados. Com base nos materiais, identificou-se o interesse da comunidade acadêmica em discutir a formação profissional de Psicologia perpassando por análises curriculares e pelas transformações históricas produzidas. Há também trabalhos que versam sobre o tema da violência, intolerância e racismo por motivações religiosas. Quanto às considerações finais, embora não tenha sido localizado pesquisas que tratem diretamente da formação profissional de psicologia frente a situações de violência religiosa, intolerância religiosa e racismo religioso, os resultados permitiram aproximação de temas discutidos pelos autores e confirmam a pertinência da pesquisa em desenvolvimento
\end{abstract}

Palavras-chave: Estado da Questão; Formação Profissional; Violência Religiosa; Currículo.

\begin{abstract}
It is a state of the question that seeks to understand the scenario of research on professional training in Psychology in the face of situations of religious violence, religious intolerance and religious racism. To this end, methodologically, the Brazilian Digital Library of Theses and Dissertations - BDTD between 2010 and 2020 was adopted as a research source. In addition, keywords were used in the search field as a way of selecting the collected materials. After that, an initial reading of the results was made in which the researcher observed the title and summary of the research, resulting in a lower percentage of materials, dissertations and theses, which were read in full and presented in the results. Based on the materials, it was identified the interest of the academic community in discussing the professional formation of Psychology, going through curricular analysis and the historical transformations produced. There are also works that deal with the theme of violence, intolerance and racism for religious reasons. As for the final considerations, although research that deals directly with the professional formation of psychology in the face of situations of religious violence, religious intolerance and religious racism has not been found, the results allowed the
\end{abstract}

\footnotetext{
${ }^{1}$ Professor do curso de psicologia (UNILEÃO)

*marcosteles@leaosampaio.edu.br

2 Professor permanente do Programa de Pós-Graduação em Ensino em Saúde (UNILEÃO)
} 
approximation of themes discussed by the authors and confirm the relevance of the research under development.

Keywords: State of the Question; Professional qualification; Religious Violence; Curriculum.

\section{INTRODUÇÃO}

O Estado da Questão (EQ) é um processo metodológico que permite ao pesquisador uma leitura de como um tema de pesquisa vem sendo discutido e tratado na comunidade acadêmica a partir de um levantamento das bibliografias já publicadas em dado momento histórico (NÓBREGA-THERRIEN; THERRIEN, 2004).

Esse levantamento é de grande valia pois permite ao pesquisador situar-se em meio a um universo bastante abrangentes de pesquisas, percursos metodológicos e resultados de publicação. Percebendo o alcance desse tipo de levantamento, este artigo objetivou realizar um Estado da Questão acerca de pesquisas sobre o currículo de formação em Psicologia que tratem de temas vinculados a violência por motivação religiosa, incluindo nesse processo a intolerância religiosa e o racismo religioso.

O pesquisador reconheceu esse processo enquanto uma etapa auxiliar a realização da sua pesquisa do Programa de Mestrado Profissional em Ensino em Saúde da Unileão, localizado na cidade de Juazeiro do Norte-CE, vinculada a linha de Políticas de Saúde, Currículo, Formação Profissional e Processos de Ensino e Aprendizagem em Saúde. Essa linha de pesquisa busca compreender os processos de formação e atuação profissional dos profissionais que estejam inseridos nos contextos de Saúde. Por esta razão, inclui estudos de políticas de currículo e o impacto desses sobre os processos formativos (UNILEÃO, 2020).

Outro ponto levantado é a análise dos diversos contextos socioculturais em que são construídas as formações profissionais, observando a necessidade de incorporar a dimensão de uma formação ética, comprometida com Direitos Humanos e a garantia da diversidade como uma expressão fundamental e legitimamente humana.

Além da aproximação temática, essa proposta permitiu compreender de que forma as publicações têm dialogado com o tema de pesquisa, assim como conhecer autores, programas de pós-graduação que tem buscado compreender temáticas relacionadas. Para isso, traçou-se critérios metodológicos de busca de dados e realizou análises e discussões que serão apresentados a seguir. 


\section{PROCEDIMENTOS METODOLÓGICOS}

Metodologicamente, este Estado da Questão utilizou a Biblioteca Digital Brasileira de Teses e Dissertações (BDTD) sugiro utilizar parêntese ao invés de traço como fonte de pesquisa para dissertações e teses hospedadas na plataforma, pertencentes a diferentes cursos de pós-graduação de instituições brasileiras públicas e privadas.

Adotou-se um conjunto de palavras-chave para utilizar no campo de busca e busca avançada, sendo elas: Psicologia", "currículo", "formação profissional”, "violência", "religião", "violência religiosa", "intolerância religiosa" e "racismo religioso", associando os descritores entre eles. As palavras-chave foram distribuídas em posições mudadas com o intuito de um possível aparecimento de novos resultados o que não veio acontecer. No entanto, o pesquisador optou sobre esse processo na busca da possibilidade de outros possíveis resultados.

Quantos aos critérios temporais, utilizou publicações pertencentes aos anos de 2010 a 2020, abrangendo dez anos de pesquisas publicadas e disponíveis na BDTD. O período de coleta das informações, leitura dos materiais e análise das produções se deu entre junho de 2019 a julho de 2020. A partir dos critérios descritos, a BDTD apontou para sessenta e sete possíveis resultados. Logo, o pesquisador realizou a leitura do título e do resumo das pesquisas apontadas nos resultados. Após isso, verificou-se que, de fato, oito pesquisas dialogam como o tema apontado no objeto desse artigo. Assim, foram feitas leituras na íntegra, organizados em categorias e discutidos os resultados (NÓBREGA-THERRIEN; THERRIEN, 2004).

\section{RESULTADOS E DISCUSSÃO}

As categorias apresentas a seguir foram elaboradas a partir das estruturas de dissertações e teses lidas ao longo do processo de elaboração desse Estado da Questão.

3.1 CATEGORIA: AUTOR, TÍTULO, ANO DE PUBLICAÇÃO E PROGRAMA DE PÓS-GRADUAÇÃO 
Essa categoria buscou reconhecer os lugares em que as pesquisas estão desenvolvidas. Além disso, identificar também suas autorias, os programas vinculados, assim como as regiões pertencentes a estes programas de pós-graduação.

Quadro 1 - Autor, título, ano de publicação e programa de pós-graduação centralizar

\begin{tabular}{|c|c|c|c|}
\hline AUTOR & TÍTULO & $\begin{array}{l}\text { ANO DE } \\
\text { PUBLICAÇÃO }\end{array}$ & $\begin{array}{l}\text { PROGRAMA DE PÓS- } \\
\text { GRADUAÇÃO }\end{array}$ \\
\hline $\begin{array}{l}\text { Aline Renata } \\
\text { Machado }\end{array}$ & $\begin{array}{l}\text { Supervisão e temas de religião: } \\
\text { experiência do acolhimento }\end{array}$ & 2010 & $\begin{array}{l}\text { Mestrado em Psicologia - } \\
\text { Pontifícia Universidade } \\
\text { Católica de São Paulo }\end{array}$ \\
\hline $\begin{array}{l}\text { Pablo de Sousa } \\
\text { Seixas }\end{array}$ & $\begin{array}{l}\text { A Formação Graduada em } \\
\text { Psicologia no Brasil: reflexão } \\
\text { sobre os principais dilemas em } \\
\text { um contexto Pós-DCN }\end{array}$ & 2014 & $\begin{array}{l}\text { Doutorado em Psicologia da } \\
\text { Universidade Federal do Rio } \\
\text { Grande do Norte }\end{array}$ \\
\hline $\begin{array}{l}\text { Danilo Oliveira } \\
\text { e Silva }\end{array}$ & $\begin{array}{l}\text { Formação, ideologia e } \\
\text { emancipação: nexos com as } \\
\text { diretrizes curriculares (2004 e } \\
\text { 2011) para os cursos de } \\
\text { graduação em Psicologia }\end{array}$ & 2015 & $\begin{array}{l}\text { Mestrado em Educação - } \\
\text { Universidade Federal de Goiás }\end{array}$ \\
\hline $\begin{array}{l}\text { Wesley dos } \\
\text { Santos Ribeiro }\end{array}$ & $\begin{array}{l}\text { Intolerância religiosa e } \\
\text { violência, frente às práticas } \\
\text { religiosas no brasil, no século } \\
\text { XXI }\end{array}$ & 2017 & $\begin{array}{l}\text { Mestrado em Ciências da } \\
\text { Religião - Pontifícia } \\
\text { Universidade Católica de Goiás }\end{array}$ \\
\hline $\begin{array}{l}\text { Vivian } \\
\text { Fukumasu } \\
\text { Cunha }\end{array}$ & $\begin{array}{l}\text { Religiosidade/Espiritualidade } \\
\text { (R/E) na prática clínica } \\
\text { psicológica: Experiências de } \\
\text { psicoterapeutas }\end{array}$ & 2017 & $\begin{array}{l}\text { Mestrado em Psicologia- } \\
\text { Programa de Pós-Graduação } \\
\text { em Psicologia, Universidade } \\
\text { Federal do Triângulo Mineiro }\end{array}$ \\
\hline $\begin{array}{l}\text { Reimy Solange } \\
\text { Chagas }\end{array}$ & $\begin{array}{l}\text { Sabe com quem está falando? } \\
\text { A ausência de conhecimentos } \\
\text { multiculturais na formação de } \\
\text { psicólogos }\end{array}$ & 2017 & $\begin{array}{l}\text { Doutorado em Psicologia: } \\
\text { Psicologia Social - Pontifícia } \\
\text { Universidade Católica de São } \\
\text { Paulo }\end{array}$ \\
\hline $\begin{array}{l}\text { Cristiane Rosa } \\
\text { Campos }\end{array}$ & $\begin{array}{l}\text { Intolerância religiosa e } \\
\text { racismo: vivências de } \\
\text { psicólogos em cultos afro- } \\
\text { brasileiros }\end{array}$ & 2019 & $\begin{array}{l}\text { Dissertação (Mestrado) } \\
\text { Faculdade de Filosofia, } \\
\text { Ciências e Letras de Ribeirão } \\
\text { Preto, Universidade de São } \\
\text { Paulo }\end{array}$ \\
\hline
\end{tabular}

Fonte: Elaborado pelo autor

Conforme o Quadro 1, foi observado que as publicações conforme os descritores utilizados aconteceram entre 2010 e 2019. A maioria dos programas de pós-graduação, seja mestrado ou doutorado, estão vinculados a área de Psicologia, seguido de outras áreas como Educação e Ciências da Religião. Destaca-se ainda o fato de não haver números expressos de pesquisas sobre essas temáticas durante o tempo que foi analisado.

Quanto às regiões, nota-se que as pesquisas estão vinculadas a programas das regiões centro-oeste, nordeste e sudeste, mais precisamente, destaca-se o estado de São Paulo com mais resultados. Quanto ao aspecto público e privado, nota-se que a maioria das produções estão vinculados a programas de universidades públicas. 


\subsection{CATEGORIA: OBJETIVOS DE PESQUISA}

Essa categoria buscou compreender os objetivos de pesquisa elaborada pelos autores das pesquisas. Ao fazer a leitura dos títulos e, posteriormente, os trabalhos na integra, percebeu-se que o uso os descritores levaram a resultados que dialogam com pesquisas sobre formação profissional em psicologia, estudos curriculares de formação em psicologia e estudos que retratam questões como violência por motivação religiosa, racismo religioso e intolerância religiosa.

Quadro 2 - Objetivo da pesquisa

\begin{tabular}{|c|c|c|}
\hline AUTOR & TÍTULO & OBJETIVOS \\
\hline Aline Renata Machado & $\begin{array}{l}\text { Supervisão e temas de religião: } \\
\text { experiência do acolhimento }\end{array}$ & $\begin{array}{l}\text { Conhecer e compreender a } \\
\text { experiência do supervisor que } \\
\text { lida com o tema Psicologia e } \\
\text { Religião com seus estagiários } \\
\text { na clínica-escola de forma a } \\
\text { que estes se sintam acolhidos. }\end{array}$ \\
\hline Pablo de Sousa Seixas & $\begin{array}{l}\text { A Formação Graduada em Psicologia } \\
\text { no Brasil: reflexão sobre os } \\
\text { principais dilemas em um contexto } \\
\text { Pós-DCN }\end{array}$ & $\begin{array}{l}\text { Investigar, em um contexto } \\
\text { pós-DCN, como os cursos de } \\
\text { graduação em Psicologia no } \\
\text { Brasil tem lidado com dilemas } \\
\text { da formação. }\end{array}$ \\
\hline Danilo Oliveira e Silva & $\begin{array}{l}\text { Formação, ideologia e emancipação: } \\
\text { nexos com as diretrizes curriculares } \\
\text { (2004 e 2011) para os cursos de } \\
\text { graduação em Psicologia }\end{array}$ & $\begin{array}{l}\text { Desvelar os nexos implicados } \\
\text { na construção das Diretrizes } \\
\text { Curriculares que regem } \\
\text { oficialmente a formação para a } \\
\text { graduação em Psicologia. }\end{array}$ \\
\hline Wesley dos Santos Ribeiro & $\begin{array}{l}\text { Intolerância religiosa e violência, } \\
\text { frente às práticas religiosas no brasil, } \\
\text { no século XXI }\end{array}$ & $\begin{array}{l}\text { Investigar características de } \\
\text { intolerância religiosa pela } \\
\text { formação sociocultural, pelo } \\
\text { conhecimento das diferentes } \\
\text { culturas. }\end{array}$ \\
\hline Vivian Fukumasu Cunha & $\begin{array}{l}\text { Religiosidade/Espiritualidade }(\mathrm{R} / \mathrm{E}) \\
\text { na prática clínica psicológica: } \\
\text { Experiências de psicoterapeutas }\end{array}$ & $\begin{array}{l}\text { Conhecer o modo como } \\
\text { psicoterapeutas experienciam a } \\
\text { Religiosidade e espiritualidade } \\
\text { em suas vidas pessoais e como } \\
\text { tal dimensão se relaciona com o } \\
\text { trabalho em Psicologia Clínica. }\end{array}$ \\
\hline Reimy Solange Chagas & $\begin{array}{l}\text { Sabe com quem está falando? A } \\
\text { ausência de conhecimentos } \\
\text { multiculturais na formação de } \\
\text { psicólogos }\end{array}$ & $\begin{array}{l}\text { Pretende-se verificar e analisar } \\
\text { os Projetos Políticos } \\
\text { Pedagógicos - PPP - de uma (1) } \\
\text { universidade pública e uma (1) } \\
\text { universidade privada, com a } \\
\text { oferta deste curso no Estado } \\
\text { São Paulo. Pretende-se ainda } \\
\text { analisar as Diretrizes Nacionais } \\
\text { Curriculares para os cursos de } \\
\text { psicologia no Brasil, e os } \\
\text { modos que estas resvalam nas } \\
\text { disciplinas e nos conteúdos } \\
\text { impactando a formação. }\end{array}$ \\
\hline
\end{tabular}




\begin{tabular}{|l|l|l|}
\hline Cristiane Rosa Campos & $\begin{array}{l}\text { Intolerância religiosa e racismo: } \\
\text { vivências de psicólogos em cultos } \\
\text { afro-brasileiros }\end{array}$ & $\begin{array}{l}\text { Elencar e descrever os efeitos } \\
\text { da inserção de psicólogos em } \\
\text { cultos afro-brasileiros e suas } \\
\text { decorrências vividos na sua } \\
\text { vida pessoal e profissional. }\end{array}$ \\
\hline
\end{tabular}

Fonte: Elaborado pelo autor

Machado (2010) na dissertação de mestrado intitulada "Supervisão e temas de religião: experiência do acolhimento", adotou como objetivo de pesquisa investigar a vivencias de uma professora-supervisora de uma clínica-escola de Psicologia, apontada pelos discentes da instituição como alguém que atua de forma acolhedora quanto ao tema.

Seixas (2014), a partir da tese de doutorado “A formação graduada em Psicologia no Brasil: Reflexão sobre os Principais Dilemas em contexto pós- DCN”, Programa de Pós-Graduação em Psicologia, estipulou enquanto objetivo: "investigar, em um contexto pós- DCN, como os cursos de Psicologia no Brasil tem lidado com os dilemas da formação" (SEIXAS, 2014, p.133), incluindo a análise de PPCs - Projeto Político Pedagógicos dos Cursos e as influências da política brasileira de ensino superior sobre a formação em Psicologia.

Silva (2015) em sua dissertação vinculada ao programa de Mestrado de Educação com o título "Formação, Ideologia e Emancipação: nexos com as Diretrizes Curriculares (2004 e 2011) para os cursos de graduação em Psicologia" buscou, enquanto objetivo, analisar os aspectos da formação em Psicologia com base nas Diretrizes Curriculares Nacionais, considerações questões sócio-político-econômico-históricos, quer dizer, uma ampla análise de conjuntura dessa época.

Ribeiro (2017) produziu uma dissertação vinculada ao programa de Mestrado em Ciências da Religiosa cujo título é "Intolerância religiosa e violência, frente as práticas religiosas no Brasil, no século XXI”. O autor traçou como objetivo investigar as formas de intolerâncias religiosas na formação sociocultural no cenário brasileiro. Assumiu como problema de pesquisa: "a hostilidade religiosa no país está relacionada a elementos históricos, éticos e culturais?” (p. 12).

Cunha (2017) com a dissertação "Religiosidade/Espiritualidade (R/E) na prática clínica psicológica: Experiências de psicoterapeutas”, Programa de Pós-Graduação em Psicologia, buscou "compreender como questões relacionadas à $\mathrm{R} / \mathrm{E}$ apresentam-se no contexto clínico de profissionais da Psicologia e a maneira como tais psicoterapeutas percebem, consideram e/ou incorporam tais aspectos em sua prática" (CUNHA, 2017, p. 
18). A partir da experiência de 24 psicoterapeutas dos estados de São Paulo e Minas Gerais.

Chagas (2017) na tese de doutorado intitulada "Sabe com quem você está falando? A ausência de conhecimentos multiculturais na formação de psicólogos”, Programa de Pós-graduação em Psicologia Social adotou como objetivo: "refletir sobre a ausência de conhecimentos multiculturais na formação de psicólogos (as), tendo como referência inicial a história e o desenvolvimento da psicologia brasileira" (CHAGAS, 2017, p. 8).

Campos (2019) na sua dissertação de mestrado chamada "Intolerância religiosa e racismo: vivências de psicólogos em cultos afro-brasileiros", no Programa de PósGraduação em Psicologia, objetivou: "elencar e descrever os efeitos da inserção de psicólogos em cultos afro-brasileiros e suas decorrências vividos na sua vida pessoal e profissional (CAMPOS, 2019, p. 34). Além do objetivo de pesquisa, é interessante mencionar que a pesquisa aponta a implicação direta entre os a intolerância religiosa e o racismo religioso em se tratando da realidade brasileira.

Quanto a pesquisa do autor em desenvolvimento, traçou-se enquanto objetivo analisar a atuação e formação de profissional de Psicologia acerca de demandas de Violência por Motivação Religiosa a partir de profissionais graduados no interior do Ceará e Sertão Pernambucano.

\subsection{CATEGORIA: PERCURSOS METODOLÓGICOS}

A categoria Percursos Metodológicos buscou compreender como os pesquisadores desenvolveram os diferentes tipos de pesquisas, objetivos, instrumentos de coleta de dados, população e a maneira como os dados foram analisados.

Quadro 3 - Autor, título e metodologia

\begin{tabular}{|l|l|l|}
\hline AUTOR & TÍTULO & METODOLOGIA \\
\hline Aline Renata Machado & $\begin{array}{l}\text { Supervisão e temas de religião: } \\
\text { experiência do acolhimento }\end{array}$ & $\begin{array}{l}\text { Pesquisa qualitativa, do tipo } \\
\text { Pesquisa fenomenológica. } \\
\text { Escolha intencional da } \\
\text { participante da pesquisa. }\end{array}$ \\
\hline Pablo de Sousa Seixas & $\begin{array}{l}\text { A Formação Graduada em Psicologia } \\
\text { no Brasil: reflexão sobre os } \\
\text { principais dilemas em um contexto } \\
\text { Pós-DCN }\end{array}$ & $\begin{array}{l}\text { Análise da literatura no campo } \\
\text { educacional a partir dos } \\
\text { Projetos Pedagógicos dos } \\
\text { cursos de Psicologia no Brasil. }\end{array}$ \\
\hline Danilo Oliveira e Silva & $\begin{array}{l}\text { Formação, ideologia e emancipação: } \\
\text { nexos com as diretrizes curriculares } \\
\text { (2004 e 2011) para os cursos de } \\
\text { graduação em Psicologia }\end{array}$ & $\begin{array}{l}\text { Pesquisa bibliográfico- } \\
\text { documental a partir de } \\
\text { documentos oficiais, as } \\
\text { Diretrizes Curriculares }\end{array}$ \\
\hline
\end{tabular}




\begin{tabular}{|l|l|l|}
\hline & & $\begin{array}{l}\text { Nacionais para os Cursos de } \\
\text { Psicologia (2004-2011). }\end{array}$ \\
\hline Wesley dos Santos Ribeiro & $\begin{array}{l}\text { Intolerância religiosa e violência, } \\
\text { frente às práticas religiosas no brasil, } \\
\text { no século XXI }\end{array}$ & $\begin{array}{l}\text { Pesquisa bibliográfica, } \\
\text { qualitativa, a partir de textos } \\
\text { impressos e digitais, finalidade } \\
\text { investigativa e explicativa, de } \\
\text { abordagem direta, pelo método } \\
\text { dedutivo e comparativo. }\end{array}$ \\
\hline Vivian Fukumasu Cunha & $\begin{array}{l}\text { Religiosidade/Espiritualidade (R/E) } \\
\text { na prática clínica psicológica: } \\
\text { Experiências de psicoterapeutas }\end{array}$ & $\begin{array}{l}\text { Pesquisa empírica, exploratória, } \\
\text { amparada na abordagem } \\
\text { qualitativa de pesquisa, de corte } \\
\text { transversal. Foi entrevistado 24 } \\
\text { psicólogos clínicos. }\end{array}$ \\
\hline Reimy Solange Chagas & $\begin{array}{l}\text { Sabe com quem está falando? A } \\
\text { ausência de conhecimentos } \\
\text { multiculturais na formação de } \\
\text { psicólogos }\end{array}$ & $\begin{array}{l}\text { Pesquisa documental, do tipo } \\
\text { qualitativa. Documentos } \\
\text { analisados: Projeto Político } \\
\text { Pedagógicos dos Cursos de duas } \\
\text { instituições de ensino de } \\
\text { Psicologia. }\end{array}$ \\
\hline Cristiane Rosa Campos & $\begin{array}{l}\text { Intolerância religiosa e racismo: } \\
\text { vivências de psicólogos em cultos } \\
\text { afro-brasileiros }\end{array}$ & $\begin{array}{l}\text { Estudo qualitativo, exploratório, } \\
\text { baseado na etnopsicologia. } \\
\text { Tiveram como participantes da } \\
\text { pesquisa onze psicólogos. }\end{array}$ \\
\hline
\end{tabular}

Fonte: Elaborado pelo autor

Machado (2010) traçou uma pesquisa fenomenológica com a escolha intenção da participante. A postura individual da professora, incluindo visão de homem e processo pessoal frente à religião foram elementos identificados como importantes no trabalho dela enquanto supervisora de Psicologia. Essa pesquisa aponta que características pessoais do profissional podem sim influenciar a maneira como é conduzido suas práticas de trabalho, no caso, temas sobre religiosidade.

Seixas (2014) realizou o percurso metodológico de sua tese tecendo considerações sobre o tema do compromisso social da Psicologia defendido há 60 anos e como conseguiu se fazer presente nos currículos brasileiros de graduação em Psicologia. Outro ponto importante observado na coleta dos dados, processo em que ficou evidente a dificuldade encontrada pelo autor de acessar os PPCs das instituições de ensino do país. Em diversos casos, o mesmo não obteve retorno de contatos ou solicitados de acesso a esses documentos.

Silva (2015) utilizou-se uma análise de documentos oficiais acerca das Diretrizes Curriculares vinculadas à Psicologia. Além disso, analisou-se documentos históricos sobre a formação profissional incluindo categorias filosóficas e cientificas. O pesquisador identificou contradições nessas categorias formuladas como as noções especialistas e generalistas da formação. 
Ribeiro (2017) baseou-se, em termos metodológicos, uma pesquisa bibliográfica, qualitativa, a partir de materiais já produzidos pela temática proposta. A partir disso, desenvolveu análises sobre o cenário da intolerância religiosa e a violência a partir de práticas religiosas no cenário brasileiro.

O método adotado por Cunha (2017) baseou-se na realização de uma pesquisa empírica, campo, com objetivos exploratórios e do tipo qualitativa. O público da pesquisa foram vinte e quatro psicólogos com pelo menos três anos de formação, estando localizados no interior de dois estados: São Paulo e Minas Gerais. O número de amostragem se deu por critério de saturação, quer dizer, no momento em que o material coletado foi compatível com os objetivos da pesquisa ou na circunstância de repetições consideráveis entre as respostas.

O percurso metodológico da pesquisa realizada por Chagas (2017) compreendeu três fases fundamentais: primeira fase - marcada pela coleta de dados sobre o conceito de multiculturalismo, compreendendo elementos de pesquisa bibliográfica e documental; segunda fase- feita de forma campal por meio de pesquisa participante acontecida em fase de estágio doutoral e do curso de pós-graduação realizados na França; terceira fase coleta de dados por meio de entrevistas com coordenadores de curso e docentes.

$\mathrm{Na}$ pesquisa realizada por Campos (2019), caracterizou-se como um estudo qualitativo e objetivo exploratório. Tiveram a participação de onze psicólogos que relataram e compartilharam suas vivências em cultos afro-brasileiros e como essa identidade produzia efeitos sobre o exercício profissional enquanto psicólogo(a). Estes participantes foram selecionados por meio da técnica "bola de neve" ou por indicação ou outros colegas da autora que são também pesquisadores, abrangeu participantes das cidades de São Paulo, de Ribeirão Preto e Porto Alegre. O material foi interpretado a partir do referencial teórico da psicanálise lacaniana.

A Etnopsicologia na qual a pesquisador foi inserida ao contexto da pesquisa, em que um total de onze psicólogos compartilharam suas experiências de pertencimento a religiões de matrizes afro-brasileiras e os efeitos dessas experiências também na atuação profissional em Psicologia. Os resultados permitiram reflexões sobre a necessidade de ouvir e dar voz as religiões ainda silenciadas pelo efeito do racismo religioso, evocando importantes temas transversais como ancestralidade, militância e família.

A metodologia adotada pela pesquisa em curso se deu através da construção da dissertação por meio da coletânea de quatro artigos científicos capazes de responder aos objetivos da pesquisa, destacando aqui a realização desse Estado da Questão, duas 
pesquisas bibliográficas dando profundidades conceituais e; por fim, uma pesquisa de campo com profissionais de Psicologia formados nos interiores do Ceará e do Sertão Pernambucano.

\section{CONSIDERAÇÕES FINAIS}

O referido da Estado da Questão permitiu apontar alguns caminhos que foram trilhados por diversos pesquisadores de diferentes regiões do Brasil. A partir das palavraschaves que foram utilizadas e a fonte de busca escolhida, percebeu-se que a maioria das produções localizadas estão relacionadas a programas de pós-graduação em Psicologia.

Quanto aos procedimentos metodológicos, identificou-se a utilização de diversos formatos de pesquisa como estudos de caso, pesquisas bibliográficas, documentais, campo e Etnopsicologia. Em se tratando diretamente das pesquisas de formação profissional, destaca-se a importância dada as Diretrizes Curriculares Nacionais como fonte de análise e outros elementos importantes que compreendem o conceito de currículo que inclui a experiência de profissionais que atuam no ensino de psicologia e a própria experiência discente.

Já as pesquisas que tratam de temas como violência religiosa, racismo religioso e intolerância religiosa permitiram uma melhor aproximação temática, possibilitando conhecer discussões, temas e autores que tratam esses temas com profundidade.

Não foi localizada nessa busca nenhuma pesquisa que dialogasse diretamente com a formação profissional de psicologia frente à violência, intolerância e racismo por motivações religiosas, mas apontou temas transversais com significativas contribuições ao tema e condições metodológicas necessárias aos estudos de currículo de formação profissional. Os achados permitem compreender a relevância na continuidade de processos investigativos sobre o tema delimitado. Permite também compreender o ineditismo da pesquisa em desenvolvimento que motivou a realização desse EQ.

\section{REFERÊNCIAS}

CAMPOS, C. R. Intolerância religiosa e racismo: vivências de psicólogos em cultos afro-brasileiros. Dissertação (Mestrado) Faculdade de Filosofia, Ciências e Letras de Ribeirão Preto, Universidade de São Paulo, Ribeirão Preto, São Paulo, 2019.

CHAGAS, Reimy Solange. Sabe com quem está falando? A ausência de 
conhecimentos multiculturais na formação de psicólogos. Teses (Doutorado em Psicologia: Psicologia Social)- Programa de Estudos Pós-graduação em Psicologia: Psicologia Social, Pontifícia Universidade Católica de São Paulo, São Paulo, 2017.

CUNHA, Vivian Fukumasu. Religiosidade/Espiritualidade (R/E) na prática clínica psicológica: Experiências de psicoterapeutas. Dissertação (Mestrado em Psicologia) Programa de Pós-Graduação em Psicologia, Universidade Federal do Triângulo Mineiro, Uberaba, 2017.

MACHADO, Aline Renata. Supervisão e temas de religião: experiência do acolhimento. Dissertação (Mestrado em Psicologia) - Pontifícia Universidade Católica de São Paulo, São Paulo, 2010.

NÓBREGA- THERRIEN, S. M.; THERRIEN, J. Trabalhos científicos e o Estado da Questão: reflexões metodológicas. In: Estudos em Avaliação Educacional, vol. 15, $\mathrm{n}^{\mathrm{o}}$ 30, jul-dez, 2004.

RIBEIRO, Wesley dos Santos. Intolerância religiosa e violência, frente às práticas religiosas no brasil, no século XXI. Dissertação (Programa de Pós-Graduação STRICTO SENSU em Ciências da Religião) - Pontifícia Universidade Católica de Goiás, Goiânia - GO,2017.

SEIXAS, Pablo de Sousa. A Formação Graduada em Psicologia no Brasil: reflexão sobre os principais dilemas em um contexto Pós-DCN. Tese de doutorado inédito. Programa de Pós-Graduação do Centro de Ciências Humanas, Letras e Artes, UFRN, Natal, 2014.

SILVA, D. O. Formação, ideologia e emancipação: nexos com as diretrizes curriculares (2004 e 2011) para os cursos de graduação em Psicologia. 2015. 107 f. Dissertação (Mestrado em Educação) - Universidade Federal de Goiás, Goiânia, 2015.

UNILEÃO. Centro Universitário Leão Sampaio. Mestrado Profissional em Ensino em Saúde. Disponível em: https://unileao.edu.br/mestrado/mestrado-profissional-emensino-em-saude/. Acesso em 17 de agosto de 2020. 